\title{
O ensino de texto nos anos de 1970 no Brasil: das técnicas linguístico-cognitivas como políticas linguísticas
}

\author{
Luciano Novaes Vidon ${ }^{1}$
}

\begin{abstract}
We have tried to discuss in this article how structuralist-formalist and functionalist conceptions reverberated in political linguistics for Portuguese teaching in Brazil throughout the 1970s and early 1980s. For this, we have analyzed a compendium published by MEC in 1981, the book " $\mathrm{O}$ Ensino de Língua Portuguesa e Literatura Brasileira no $2^{\circ} \mathrm{Grau}$ - sugestões metodológicas", a kind of Curricular Parameters of that period, which reflects and refracts, on the one hand, the hegemonic language conception, officially defended by the The Ministry of Education and Culture, and, on the other hand, language and teaching concepts supported by different theories that occupied, at that moment, the academic discursive arena in the areas of Linguistics and Education in Brazil. From this confrontation, tense and contradictory, as it could not fail to be, a technicist vision of text teaching (writing) stands out, based on a psychology at the same time innatist and behavioral, that, in a certain way, seems to haunt us until the days current. The reflections are based on the Bakhtinian studies, under a socio-historical bias.
\end{abstract}

Keywords: Text teaching; Language policy; Years 70-80; Dialogism.

Resumo: Procuramos discutir neste artigo como concepções estruturalistas-formalistas e funcionalistas reverberaram na política linguística para o ensino de língua portuguesa no Brasil ao longo dos anos de 1970 e início dos anos de 1980. Para isso, analisamos um compêndio publicado pelo MEC em 1981, o livro "O ensino de língua portuguesa e literatura brasileira no $2^{\circ}$ grau - Sugestões metodológicas”, uma espécie de Parâmetros Curriculares de sua época, que reflete e refrata, de um lado, a concepção de língua(gem) hegemônica, defendida oficialmente pelo Ministério da Educação e Cultura, e, de outro, concepções de língua(gem) e de ensino defendidas por diferentes teorias que ocupavam, naquele momento, a arena discursiva acadêmica nas áreas de Linguística e Educação no Brasil. Desse embate, tenso e contraditório, como não poderia deixar de ser, sobressai uma visão tecnicista de ensino de texto (redação), com base em uma psicologia ao mesmo tempo inatista e comportamental, que, de certa forma, parece nos assombrar até os dias atuais. As reflexões se dão com base nos estudos bakhtinianos, sob um viés sócio-histórico.

Palavras-chave: Ensino de texto; Política linguística; Anos 70-80; Dialogismo.

1 Professor Associado do Departamento de Línguas e Letras e Coordenador do Programa de Pós-Graduação em Liguística da UFES. Coordenador do Grupo de Estudos Bakhtinianos (GEBAKH) UFES. Membro do Grupo de Pesquisa: "Histórias das Ideias: Diálogos entre Sociedade, Sujeito e Linguagem" UFRGS. 


\section{Introdução}

Os anos de 1970, no Brasil, são marcados por acontecimentos que, direta ou indiretamente, influenciaram o ensino de língua portuguesa e, mais especificamente, o ensino de texto (leitura e redação) nas escolas públicas e particulares brasileiras por muito tempo e, quiçá, influenciam até os dias de hoje.

Um desses acontecimentos foi a promulgação do Decreto-Lei n ${ }^{\circ} 5692$, em 1971, que, no âmbito de uma política de Estado desenvolvimentista, estabelecia as diretrizes e bases nacionais para a Educação, concebendo a língua(gem) como instrumento de comunicação e expressão da cultura brasileira.

Importa rememorar que esse contexto histórico foi marcado por um Golpe de Estado no ano de 1964, que retirou do poder o presidente legítimo, João Goulart, e implantou um governo militar ditatorial, regido por generais do exército brasileiro. Nesse horizonte axiológico, assim como em outros períodos em que governos totalitários (explícitos ou não) assumiram o poder, a educação e a língua(gem) se tornam alvos de políticas governamentais. No caso do governo militar pós-golpe de 1964, os interesses se voltaram especialmente para a formação de mão-de-obra especializada para a indústria e o mercado neoliberal emergentes no Brasil, sob a égide, particularmente, do governo norte-americano.

Renegando, no âmbito sócioeconômico, as reformas de base do governo João Goulart, no plano educacional, os militares se contrapõem às ideias defendidas por educadores como Paulo Freire, que propunham uma educação emancipadora, valorizando a educação pública e gratuita, democrática e com ativa participação dos professores e da comunidade escolar. Na contramão dessas ideias, o Ministério da Educação e Cultura pós-golpe de 1964 se volta para o ensino tecnicista-profissionalizante e para a mercantilização da educação. É nesse contexto que se elabora e se promulga a LDB 5692, em 1971.

A LDB 5692/1971 é, a nosso ver, o primeiro grande documento de política linguística elaborado por um governo brasileiro. Documentos anteriores, como a Lei ${ }^{\circ} 4024$ (Lei de Diretrizes e Bases da Educação Nacional), de 1961, não têm nem a extensão, nem os fundamentos epistêmicos dessa lei, muito menos tiveram o seu alcance social e pedagógico. Também não apresentam nenhum dispositivo legal diretamente relacionado às questões linguísticas.

Já a Nova LDB, como ficou conhecida à época, traz, em seu Art. $1^{\circ}$, com todas as letras:

No ensino de $1^{\circ}$ e $2^{\circ}$ graus, dar-se-á especial relevo ao estudo da língua nacional como instrumento de comunicação e como expressão da cultura brasileira. (BRASIL, 1971).

O Parecer 853, do Conselho Federal de Educação, também de 1971, expandia o argumento:

A Língua Portuguesa, portanto, será encarada como instrumento por excelência de comunicação no duplo sentido de transmissão e compreensão de idéias, fatos e sentimentos e sob a dupla forma oral e gráfica, o que vale dizer: leitura, escrita e comunicação oral. Nesta última encontra-se um dos elementos mais evidentes da conecção (sic) entre a língua e os Estudos Sociais, encarados como um mecanismo de integração do educando ao meio. Também não se há de esquecer, neste particular, a importância cada vez maior que assume nos dias atuais a linguagem falada, ao impacto dos meios de comunicação "audiovisual", a 
ponto de que, se já não vivemos uma cultura predominantemente oral, pelo menos as duas vias tendem a equilibrar-se. (BRASIL, 1981, p. 5)

Do ponto de vista linguístico, trata-se de um divisor de águas, já que concebe a língua(gem) como instrumento de comunicação, como pôde ser visto nas citações acima, tendo por base teorias modernas do recente campo de conhecimento denominado linguística. Nesse sentido, é importante lembrar que os cursos de Letras no Brasil introduzem a disciplina de linguística em seus currículos em meados dos anos de 1960, praticamente mesmo momento em que o $1^{\circ}$ curso de pós-graduação em Linguística é implementado no Brasil, mais especificamente na USP, em 1966 (CLARE, 2003).

Além da concepção funcionalista (instrumental) de linguagem, herdeira dos trabalhos de Roman Jakobson, mas também de outros pesquisadores, como Karl Büller, de alguma forma a LDB 5692/1971 e seus desdobramentos têm em sua base, no que tange às questões de língua, uma concepção sistêmico-formal, repercutindo trabalhos estruturalistas, como o de F. de Saussure e L. Bloomfield, e também formalistas, como o de Noam Chomsky.

O que procuramos discutir neste artigo é como essas concepções estruturalistas-formalistas e funcionalistas reverberaram na política linguística para o ensino de língua portuguesa no Brasil ao longo dos anos de 1970 e início dos anos de 1980, limiar de um outro movimento discursivo que começa a se instaurar e inverter os caminhos dessa política linguística e de suas consequentes práticas linguístico-pedagógicas.

Para isso, analisamos um compêndio publicado pelo MEC em 1981, o livro "O ensino de língua portuguesa e literatura brasileira no $2^{\circ}$ grau - Sugestões metodológicas" ${ }^{2}$, coordenado pela Profa. Magda Becker Soares e com participações de Maria Antonieta Antunes Cunha - linguagem oral e gramática -, Orlando Bianchini - redação e leitura - e Letícia Malard - leitura, uma espécie de Parâmetros Curriculares de sua época, que reflete e refrata, de um lado, a concepção de língua(gem) hegemônica, defendida oficialmente pelo Ministério da Educação e Cultura, e, de outro, concepções de língua(gem) e de ensino defendidas por diferentes teorias que ocupavam, naquele momento, a arena discursiva acadêmica nas áreas de Linguística e Educação no Brasil.

Analisamos esse documento seguindo as orientações teórico-metodológicas dos estudos bakhtinianos, em especial os princípios da historicidade, da limiaridade e da dialogicidade (BAKHTIN, 1998; BAKHTIN, 2010; BAKHTIN, 2013; BAKHTIN/VOLOCHÍNOV, 2011; VOLOSHÍNOV, 2013), em conformidade com a concepção de História proposta por Paul Veyne (1992), que investiga os fatos históricos da perspectiva das forças sociais. Desse modo, esta pesquisa buscou reconstruir historicamente um dos momentos mais importantes da história recente da Educação e do ensino de Língua Portuguesa no Brasil: a passagem dos anos de 1970 aos de 1980, período identificado por muitos como o início da 'redemocratização política no Brasil', mostrando as tensões e contradições de uma política linguística que fez emergir uma visão tecnicista de ensino de texto (redação), com base em uma psicologia ao mesmo tempo inatista e comportamental, que, de certa forma, parece nos assombrar até os dias atuais.

2 Há indícios de que essa obra fazia parte de uma série de publicações realizada pelo MEC, denominada Ensino Regular. Porém, até o momento, não conseguimos encontrar outros livros da série. A referência a essa série encontra-se na ficha bibliográfica da edição que pesquisamos. 
Uma perspectiva tecnicista de ensino de texto se instaurou no Brasil nos anos de 1970 e 1980, dando guarida a uma política econômica liberal-desenvolvimentista, na qual a formação de mão-de-obra, especialmente para uma indústria emergente, era a prioridade. Ao mesmo tempo, bases linguístico-pedagógicas formalistas e cognitivistas pareciam sustentar as concepções de língua/linguagem, texto e, também, sujeito ${ }^{3}$.

Como podemos perceber no trecho a seguir, do livro "O ensino de língua portuguesa e literatura brasileira no $2^{\circ}$ grau - Sugestões metodológicas”, organizado pela Profa. Dra. Magda Becker Soares, a serviço do Ministério da Educação e Cultura (MEC), a língua(gem) é vista como um sistema estrutural-formal, à moda chomskyana, condição sine qua non para a comunicação.

Comunicar é tornar comum. Passamos de nós, para os outros, fatos, ideias, pensamentos, emoções, sentimentos. Isso se faz verbalmente (através de palavras, que constituem frases). Tais frases são organizadas dentro de um sistema (conjunto finito de regras capaz de gerar sentenças ou frases infinitas). Assim, por exemplo, com uma regra simples que define a ordem normal da sentença em português (sujeito-verbo-complemento) podemos produzir, teoricamente, infinitas sentenças. É como na matemática; o mecanismo (ou regra) de uma operação qualquer é o mesmo para infinitas variações de dados. (BRASIL, 1981, p. 5 grifos dos autores)

Ainda que a definição de comunicação acima queira apresentar um traço social, como exercendo a função de 'mecanismo de integração do educando (indivíduo) ao meio (grupo social)', remetendo, pois, ao Parecer 853/71 do CFE, referido na seção anterior, princípios estruturalistas, como a noção de sistema, e formalistas, como a noção chomskyana de gramática - conjunto finito de regras capaz de gerar sentenças ou frases infinitas - ou mesmo de ordem sintática, mantêm uma certa tensão hierárquica nesta concepção de língua, de modo que o social, a comunicação verbal, em especial a oral, como salienta o Parecer do CFE, o indivíduo integrado ao meio ou grupo social, acaba se subordinando ao princípio gramatical (estrutural/formal) que rege o sistema. A comparação, ao final da citação destacada acima, com a matemática é um dado singular (GINZBURG, 1986) neste sentido, um indício de que uma formalização ou tecnicização do ensino de texto seria viável, a despeito dos elementos variantes em jogo.

Embora um pouco mais adiante no texto, os autores busquem associar o caráter verbal da linguagem a uma função simbólica, representacional, influência das teorias semióticas em vigor naquele contexto, a noção de verbal aqui, como podemos observar na citação anterior, é diretamente associada à língua em seu aspecto mais formal, estrutural - "Isso se faz verbalmente (através de palavras, que constituem frases)". A ligação entre o caráter verbal da língua(gem) e sua natureza social, salientada anteriormente, se perde, dado que o verbal se sobrepõe ao social.

3 Nestas bases - formalistas e cognitivistas - surgiram discursos tecnicistas em relação ao ensino de texto (redação), materializados formalmente em manuais de redação, como o longevo "Técnica de redação" (1979), de autoria de Magda Becker Soares e Edson Campos Nascimento. Assentado em uma visão geral de linguagem funcionalista jakobsoniana, na prática esse manual tem raízes cognitivistas e comportamentalistas profundas, o que revela, na verdade, uma contradição, como apontamos na análise do documento do MEC. 
Importante observar ainda que os autores reconhecem as "infinitas variações de dados", o que poderíamos entender como se referindo à(s) realidade(s) de uso(s) da(s) língua(s)/linguagem(ns), no entanto postula-se uma ordem discursiva anterior, a verbal, onde se encontraria o mecanismo operacional (matemático) do sistema.

O sujeito, por sua vez, é concebido em uma perspectiva cognitivo-desenvolvimentista. Para os autores (BRASIL, 1981, p. 7),

principalmente no $2^{\circ} \mathrm{Grau}$, quando o aluno já teria adquirido as estruturas básicas da língua, os exercícios de linguagem deveriam levar o estudante ao desenvolvimento, ampliação e variação dessas estruturas, definindo aquilo que poderíamos chamar de estilo pessoal e dando-lhe a visão de uma língua suficientemente rica para permitir (ou mesmo exigir) variações de registro, de acordo com a situação específica de cada ato de comunicação. No $2^{\circ}$ Grau, ele [o aluno] está em plena fase do pensamento racional, caracteristicamente marcado pelo domínio das noções abstratas, com grande possibilidade, consequentemente, de análise e crítica. (BRASIL, 1981, p. 7)

Vê-se que o documento concebe o sujeito em bases generalistas e linguístico-cognitivas, partindo do pressuposto de que, ao atingir determinada idade, todos os indivíduos em condições supostamente normais - teriam adquirido as "estruturas básicas da língua". Em nenhum lugar do documento, no entanto, se esclarece que estruturas básicas seriam essas e de que língua se está falando.

Essa visão psicogenética, de base piagetiana, também pode ser relacionada à afirmação final desse trecho segundo a qual no $2^{\circ}$ grau, atual ensino médio, o aluno estaria "em plena fase do pensamento racional, caracteristicamente marcado pelo domínio das noções abstratas, com grande possibilidade, consequentemente, de análise e crítica”. O condicionamento, portanto, da atividade psíquica e, consequentemente, da atividade linguística desse indivíduo (o aluno) se dá por vias psicogenéticas, com base em fases do desenvolvimento biológico e cognitivo, domínio de ações concretas e noções abstratas, o que possibilitaria comportamentos de análise e crítica. Condicionamentos sociais, históricos, culturais não são sequer mencionados no documento, ainda que se ensaie uma valoração do estilo pessoal dos alunos.

É nesta direção que o MEC, através desse dispositivo, um compêndio que visava subsidiar o professor em sua prática em sala de aula, se coloca como um documento direcionador de uma prática linguístico-pedagógica assentada em uma política linguística tecnicista e cognitivista.

Soares et alii reconhecem que a comunicação é de natureza social (no fundo, portanto, a língua(gem) também o seria) e que os textos e contextos de produção são diversificados, heterogêneos. No entanto, para fins didático-pedagógicos, a técnica exigiria a eleição de um gênero para aplicação dos fundamentos elencados ao longo do livro: a língua como um sistema formal e o estudante como um sujeito movido por comportamentos pré-determinados, como motivação, incentivação, correção e avaliação. Esses elementos constituíram, na verdade, os princípios da metodologia proposta pelos autores dos "Subsídios metodológicos".

Se existem em qualquer indivíduo - como se afirmou na Introdução deste trabalho - propensões inatas para a aprendizagem da língua (oral), o mesmo não ocorre com relação à escrita, tardia criação humana de caráter bem mais artificial. Ensinar expressão escrita (ou redação) é um trabalho que exige sistematização, continuidade e metodologia especial. E aqui se evidencia um despreparo geral. (BRASIL, 1981, p. 40) 
O compêndio do MEC não explicita de quem seria esse "despreparo geral" em relação ao ensino de redação, mas se pode inferir que se trate dos professores de língua portuguesa, considerados os principais responsável pelo "ensino da expressão escrita (ou redação)". Como saída, os autores propõem uma metodologia "comportamentalista", como discutiremos na próxima seção, com base em uma noção sistêmica de texto, adequada, assim, a uma tecnicização do ensino de redação. Como veremos a seguir, o texto (redação) também é tratado como passível de um cálculo matemático, como uma operação cognitiva racional.

Para tratar desse ponto, deter-nos-emos no capítulo "Redação" do livro organizado por Soares et alii ${ }^{4}$.

As sugestões metodológicas para o ensino de redação: técnicas de base comportamental e linguístico-cognitiva

As contradições presentes na parte introdutória do documento do MEC se acentuam no momento das propostas de intervenção linguístico-pedagógica.

Ora, se não é a psicolinguística inatista chomskyana que norteará o "desenvolvimento de operações mentais" no trabalho com redação no $2^{\circ}$ grau, há que se buscar um outro modelo do campo da psicologia para esse processo. Como veremos a seguir, trata-se de um modelo comportamentalista, cujos princípios metodológicos são: Motivação, Incentivação, Aplicação, Correção, Exercícios e Avaliação.

Dado que os autores recusaram, de início, associar o aprendizado da escrita à teoria inatista chomskyana, o que, a princípio, poderia explicar a disposição interior individual dos aprendizes, parece mais do que plausível relacionar as definições acima de motivação e incentivação a teorias comportamentalistas, o que redunda em uma contradição teórico-metodológica da proposta.

Soares et alii parecem se encontrar, neste ponto, no que Bakhtin/Volochínov denominam, em "Marxismo e filosofia da linguagem" (2011), de corrente subjetivo idealista, que teve na área da psicologia comportamental seus grandes representantes, que acabaram influenciando, também, estudiosos da linguagem, como Vossler e Spitzer, citados por Bakhtin/Volochínov (todos muito voltados para questões de estilística). É importante ressaltar que a concepção de subjetivismo idealista de Bakhtin/Volochínov está embasada em uma crítica a visões idealistas da linguagem, uma vez que o psiquismo individual somente pode ser explicado a partir de problemas concretos que se instituem no meio social.

Se não, vejamos a citação a seguir:

É desnecessário, por razões óbvias, demonstrar o valor da motivação para o resultado de qualquer trabalho. Mais útil será, acreditamos, discutir os fatores e as condições que determinam e mantêm, no aluno, esse impulso interior que o leva a querer fazer sempre melhor. (BRASIL, 1981, p. 43)

Não obstante o paradoxo acima referido, isto é, a assunção de um modelo racionalista

4 É importante observar que, no ano de 1977, o governo brasileiro, através do Ministério da Educação e Cultura, instituiu a obrigatoriedade da 'prova ou questão de redação' nos vestibulares do país, sendo, portanto, pertinente uma orientação governamental, sustentada por especialistas no assunto, sobre o ensino de redação. 
como fundamento teórico, mas a aplicação de um modelo comportamentalista na prática linguístico-pedagógica, os autores se propõem a "apresentar reflexões e sugestões que possam ajudar o professor na criação de um método próprio, adequado às suas características individuais e às condições sócio-históricas de seus alunos" (BRASIL, 1981, p. 41). É importante salientar que a noção de 'condições sócio-históricas' não havia sido evocada até então.

A hipótese que formulamos, para tentar entender essas contradições do documento, diz respeito a uma visão tecnicista, que se impunha a partir de uma visão desenvolvimentista advinda do contexto político-governamental em que o MEC estava inserido.

Pelo menos dois dados apontam nessa direção:

1) a redução do ensino de texto à redação prática;

2) o foco da metodologia nas técnicas de redação.

Na tentativa de formulação de uma metodologia de ensino de redação (ou de expressão escrita), os autores propõem as seguintes questões: Quem deve redigir? O que se deve redigir? Por que redigir? Para que redigir? Como redigir? No entanto, os autores não se detêm em maiores detalhes a respeito das quatro primeiras perguntas, que, do ponto de vista discursivo, estão mais diretamente relacionadas às condições sociais e históricas de produção. Consideram que a questão fundamental é o "como", "um processo que exigiria tempo, treinamento e metodologia adequada".

Atitude, gosto, saber, pré-disposição, afetividade, interesse, espírito de camaradagem, além dos já referidos, motivação e incentivação, são algumas das noções que compõem a presente formulação metodológica e que colocam em posição dominante a motivação interna do aluno e as questões de subjetividade individual. São, pois, signos ideológicos do universo teórico subjetivo-idealista, discutido pelo Círculo de Bakhtin, não só em "Marxismo e filosofia da linguagem" (BAKHTIN/VOLOCHINOV, 2011), como já mencionado, mas também em "O Freudismo" (BAKHTIN, 2010), "O método formal nos estudos literários" (MEDVIÉDEV, 2012), entre outras obras do círculo dos anos de 1920 e 1930.

Já em relação ao ensino de texto, apesar de chamarem a atenção para o fato de que as situações de escrita são diversas, propondo, inclusive, três tipos gerais de escritores - os que escreveriam espontaneamente, os que escreveriam circunstancialmente e os que escreveriam profissionalmente -, as 'reflexões e sugestões' irão se deter na redação escolar, concebida como um exercício de preciosismo gramatical, um treinamento para aquisição da escrita ou ensaio, uma técnica, enfim, de imitação de uma realidade própria dos textos considerados modelos do vernáculo ${ }^{5}$.

Essa redução do escopo da expressão escrita à redação escolar, a atividades escolarizadas de redação, parece entrar em contradição com a proposta de relacionar a escrita com as condições sócio-históricas dos alunos e, como descrito a seguir, com a proposta de produção de textos que remeta a diferentes situações de comunicação:

5 Tal perspectiva não parece diferir muito do ensino inicial da escrita no século XIX, que, de acordo com Mortatti (2014, p. 11), seria "ensinar um modelo de língua escrita centrado na gramática (geral e nacional) e a ser imitado, com base em modelos de texto literário de escritores consagrados. Simultaneamente, tratava-se de ensinar valores morais e cívicos, como parte do processo de escolarização diretamente relacionado com projetos políticos para a nação brasileira". 
Redação não é apenas aquele exercício proposto em dia marcado, sobre determinado assunto, com um número de linhas mais ou menos previsto. Redação é o produto do ato de redigir. Um bilhete, um aviso, uma resposta de prova, um slogan, uma piada ou 'gozação' que se faz por escrito com um colega, tudo é redação. (p. 44)

Se tudo é redação, como o excerto acima sugere, as perguntas que intrigam são: por que a redução do ensino da expressão escrita à redação escolar? E o que seria, afinal de contas, essa redação escolar?

Ao tratarem, por exemplo, da $2^{a}$ fase do processo ensino-aprendizagem de redação, denominada ora como Aplicação, ora como Incentivação e Aplicação, Soares et alii (BRASIL, 1981, p. 45) observam: "De como é aplicado o trabalho, dos incentivos externos que recebe, depende a disposição do aluno para realizá-lo e, de certa forma, seu sucesso".

Essa aplicação segue, pois, três eixos principais, um temático, voltado para o assunto sobre o qual o estudante irá se debruçar, um preparatório, entendido como estudo de texto(s), debates, pesquisas, relatos, entrevistas, material audiovisual, etc., e outro tipológico, isto é, relativo ao tipo de redação a ser exigido no $2^{\circ}$ grau.

Em relação ao primeiro eixo, a sugestão é que os temas estejam relacionados às vivências e problemas dos jovens, o que criaria neles maior disposição e interesse pela escrita. Trata-se de uma proposição interessante, mas que parece contraditória em relação aos pressupostos teóricos iniciais, estruturalistas e formalistas, que não estão se sustentando neste momento. As supostas vivências e experiências dos jovens não são discutidas, sequer exemplificadas, o que faz com que interpretemos os "incentivos externos" como o fundamento comportamentalista do "estímulo", condição sine qua non, dentro do modelo behaviorista, para uma "resposta" adequada ao processo.

No que se refere ao tipo de texto/redação, os autores partem de uma distinção que seria amplamente conhecida entre 'redação prática' e 'redação criativa', propondo substituir esta última por 'redação literária', dado que, para os autores, a criatividade linguística estaria presente em qualquer texto.

Costuma a escola fazer da redação literária um exercício mais comum, quando não exclusivo, e, no entanto, já o afirmamos, raríssimos serão os poetas ou artistas da linguagem. A quase totalidade dos alunos terá a necessidade de, em sua vida profissional, de (sic) produzir textos técnicos ou científicos, de redigir ofícios, relatórios, avisos, etc. (BRASIL, 1981, p. 46)

Neste ponto, percebemos um posicionamento contrário dos autores a práticas tradicionais de redação, como a composição literária, comum em um modelo pedagógico importado da Europa em que os estudantes buscavam imitar a expressão escrita de grandes escritores. Ao se contraporem a essa perspectiva tradicional, os autores apontam na direção de um viés tecnicista no ensino, já que elegem como gêneros preferíveis de produção textual oficios, relatórios, avisos, ou seja, gêneros do campo científico e/ou profissional.

A contraposição entre redação literária e redação prática terá uma repercussão imediata no ensino de texto no $2^{\circ}$ grau nos idos dos anos de 1970 e início dos anos de 1980: a hegemonia ideológica do texto dissertativo (poucas vezes argumentativo) no universo escolar. Logicamente, esse ideologema, no sentido de Medviédev (2012), terá o respaldo 
e o reforço do decreto de 1977 que instituiu a prova de redação como obrigatória nos vestibulares do Brasil. O texto dissertativo (ou dissertação escolar, prosa dissertativa, ou, ainda texto dissertativo-argumentativo) se tornará um ideologema que se situará entre nós (MEDVIÉDEV, 2012, p. 56).

O manual já mencionado por nós, “Técnica de redação”, de 1979, organizado por Magda Soares e Edson Nascimento, editado até os dias de hoje, fazia coro a essa ideologização ${ }^{6}$ :

É que a DISSERTAÇÃO é a forma de REDAÇÃO mais usual. Com mais freqüência é a forma de REDAÇÃO solicitada às pessoas envolvidas com a produção de trabalhos escolares, com a administração e produção de pesquisas em Instituições que fazem Ciência, com a administração e execução técnico-burocráticas de serviços ligados à Indústria, Comércio, etc. A prosa dissertativa é, assim, predominante nos textos de trabalhos escolares, nos textos de produção e divulgação científicas (monografias, ensaios, artigos e relatórios técnico-científicos) e nos textos técnicos-administrativos. Raramente é uma pessoa solicitada a produzir uma descrição ou uma narração; freqüentemente, ao contrário, é solicitada a produzir uma dissertação. [destaques dos autores]

Ao afirmarem que "a dissertação é a forma de redação mais usual", os autores não parecem estar se referindo a enunciados concretos, no sentido bakhtiniano do termo (BAKHTIN, 2013), ou seja, a gêneros discursivos realizados cotidianamente pelos sujeitos, como artigos jornalísticos, científicos ou de divulgação científica, comentários opinativos orais ou escritos, resenhas, sinopses, crônicas, cartas de leitor, etc. O que os autores parecem ter em mente é uma estrutura típica, denominada "forma de redação". No entanto, não são essas "formas", em sentido abstrato, que são solicitadas às pessoas, nas escolas, repartições públicas, nas universidades, empresas, igrejas, sindicatos, etc.

É a dissertação, portanto, o tipo de texto que melhor se encaixa na concepção de redação escolar e torna possível a aplicação das outras fases da metodologia de ensino proposta, tais como correção, exercícios e avaliação, fases posteriores a motivação/incentivação e aplicação. São fases importantes, dentro do modelo proposto, consistindo em lugares de aplicação de uma visão sistêmica, formal e estrutural de língua e de texto. Neste ponto, entendemos que, embora, em relação aos sujeitos aprendizes, a visão dos autores seja subjetivista-idealista (vide as fases de motivação, incentivação e aplicação), em relação à língua e ao texto, a concepção, tomando ainda os trabalhos do círculo de Bakhtin, é objetivista-abstrata (vide as fases finais do modelo: correção, exercícios e avaliação).

A correção, por exemplo, se concretizaria em três planos distintos: a apresentação física do texto; o conteúdo; e a expressão. Quanto ao primeiro plano, seriam observados: adequação do papel ao tipo de texto; distribuição do texto no papel; existência de título, sua posição no papel; existência de espaços indicadores de parágrafos; uso de margem; legibilidade da letra; etc. No plano do conteúdo, seriam examinados dois aspectos: a seleção e a organização de ideias. E, por fim, no plano da expressão, estariam em jogo: acen-

6 É importante pontuar que a Profa. Magda Soares, juntamente com o Prof. Edson Nascimento Campos, publicaram o livro "Técnicas de redação" no mesmo período do documento em análise ( $1^{\mathrm{a}}$ edição publicada em 1979), e propõem uma metodologia de ensino muito próxima da apresentada nas "Sugestões metodológicas". O subtítulo do livro já dá uma indicação dos seus pressupostos teóricos de base: "As articulações linguísticas como técnica do pensamento". Também analisamos essa obra como um documento importante do contexto histórico que estamos discutindo. Essa análise, no entanto, será objeto de um outro artigo. 
tuação dos vocábulos; ortografia; morfossintaxe (flexões, concordância, regência, uso de tempos e modos verbais, emprego de pronomes, etc.); estrutura dos períodos; pontuação; adequação do vocabulário; registro, etc.

Segundo os autores, no plano do conteúdo, as ideias serão examinadas de acordo com sua seleção e organização. A seleção de ideias deve seguir dois princípios básicos, suficiência e relevância, mas que não são devidamente definidos, esclarecidos, atribuindo-se ao professor a capacidade de discerni-los e orientar seus alunos. Essa questão pode ser relacionada à concepção de subjetivismo idealista: como avaliar uma redação a partir dos critérios de suficiência e relevância, colocando no centro da questão a subjetividade individual e não questões de ordem social?

Quanto à organização de ideias, três elementos entram em foco: o plano da redação; a estruturação dos parágrafos; e a constituição dos períodos. Ponderam, os autores, que "organizar é fazer os elementos funcionarem em relação a um todo e vice-versa. Se o todo é harmônico (se o todo é bom), pouco importa qual seja a disposição dos elementos no conjunto - cronológica, lógica ou psicológica" (BRASIL, 1981, p. 49). Em relação aos parágrafos, afirmam: "cada texto - voltamos a insistir - propõe suas regras, em função das quais o conjunto se estrutura. Apenas pela observação dos parágrafos no todo podemos, a posteriori, dizer se existe ou não unidade e coerência" (id.).

Vemos, assim, que a proposta dos autores não consegue ultrapassar os limites do texto, enquanto unidade linguística (e não enquanto enunciado concreto, unidade de comunicação discursiva, nos termos de Bakhtin [2013]), mesmo quando se trata de aspectos como conteúdo e expressão, que, supostamente, exigiriam uma reflexão sobre as condições sociais e históricas de produção. Ao contrário o texto é tratado como um todo harmônico, um conjunto estruturado, um sistema, enfim, cujo funcionamento se daria por clareza e coerência, como se explicita no trecho a seguir:

Clareza e coerência são os dois requisitos que devem perpassar todo o texto. E por coerência entendemos não apenas a ligação cronológica, lógica ou psicológica das idéias, mas ainda a adequação das formas linguísticas ao conteúdo e à situação do texto. (p. 51)

A 'situação do texto', referida acima, dentro desse contexto, só pode ser interpretada como situação psicolinguística do texto, e não, como poderíamos supor, situação "sociológica" ou "sociolinguística" do texto, que envolveriam questões discursivas (estilísticas) determinantes da produção textual.

Sobressai, assim, na arquitetônica das "Sugestões metodológicas", uma visão psicolinguística de texto, isto é, uma visão mais cognitivista do que sociológica do processo de produção textual e que caracterizam a realidade dos alunos, das variações de registro e das diferentes modalidades de textos.

A despeito de uma possibilidade de virada teórico-metodológica nesse processo histórico, a partir de meados dos anos de 1980, particularmente a partir da publicação de "O texto na sala de aula”, por João Wanderley Geraldi, em 1984, uma concepção psicologicista ainda é muito forte e está muito presente em nossas teorias e práticas de ensino-aprendizagem de textos. Dado singular, conforme Ginzburg (1986), é a permanência do texto dissertativo-argumentativo nas provas de redação do Exame Nacional do Ensino Médio, o Enem, ressonância ideológica do quadro que apresentamos em relação às "Sugestões metodológicas" dos anos de 1970. 
"O ensino de língua portuguesa e literatura brasileira no $2^{\circ}$ grau: sugestões metodológicas", tomado aqui como um documento histórico oficial do Ministério da Educação e Cultura, publicado em 1981, reflete e, ao mesmo tempo, refrata uma política linguístico-pedagógica implementada pelo governo brasileiro nos anos de 1970 e, de alguma forma, balizada por especialistas em linguagem e educação, como no caso das Profas. Magda Soares, Maria Antonieta Cunha, Letícia Malard e do Prof. Orlando Bianchini. Tal política linguística reflete e refrata, por sua vez, uma política econômica e social de um governo que se colocava como desenvolvimentista, alinhado às ideologias das grandes potências capitalistas mundiais daquele momento, notadamente Estados Unidos da América, países da Europa Ocidental, como Inglaterra e Itália, e Japão.

Uma tendência racionalista, positivista, portanto, atravessa as formulações do documento em questão, especialmente em relação a uma concepção estrutural-formal de língua e de texto, que sobrepõe o verbal ao social, uma visão instrumental/tecnicista de ensino de redação (baseada em um modelo comportamentalista do processo ensino-aprendizagem), um tratamento subjetivo-idealista do aluno e um tratamento tecnicista e alienante do professor.

Algumas contradições emergem do documento, como a que relaciona o linguístico verbal ao social e a flutuação entre uma posição inatista a respeito da língua, da aquisição de conhecimento linguístico e uma posição comportamentalista quando se trata do processo ensino-aprendizagem.

Tais paradoxos revelam, também, um assentamento das posições do documento em uma perspectiva mais cognitivista do que sociológica. Isso parece explicar a fundação do método em uma psicologia comportamentalista, e não em bases sociológicas, como o documento ensaia em alguns momentos. Por exemplo, ao se referir aos objetivos da metodologia sugerida, os autores dizem que serão levadas em consideração as condições sócio-históricas de professores e alunos. No entanto, toda a proposta metodológica de ensino de redação é construída sob uma base cognitivista que generaliza tanto o sujeito professor, quanto o sujeito aluno. Os conteúdos dos textos são abstraídos das situações concretas de enunciação e se reduzem a ideias a serem selecionadas e organizadas, segundo critérios também abstratos, como suficiência e relevância. Segundo os autores, seria o próprio texto (a redação) que determinaria o(s) grau(s) de suficiência e relevância das ideias selecionadas. Não seriam, portanto, as condições sócio históricas de produção discursiva que atuariam nesse processo. Por sua vez, a organização de ideias e a sua expressão se voltam para aspectos formais da língua e do texto, como estruturação dos parágrafos, constituição dos períodos, acentuação dos vocábulos, ortografia, morfossintaxe (relações de concordância, regência, emprego de pronomes, etc.), registro, etc. É exatamente nesse ponto que os autores consideram, como vimos antes, as noções de clareza e coerência como requisitos que perpassariam todo o texto. Podemos dizer que há uma dissociação entre os planos do conteúdo e da expressão, perspectiva completamente diversa da postulada por Bakhtin em "Os gêneros do discurso" (2013), e por ele e outros autores do círculo em outros textos.

Por fim, ao deslocar os seus interesses de perguntas como Quem? Por quê/para quê? Onde? e $O$ quê? para Como?, Soares et alii se posicionam no campo das técnicas de redação, e não no campo dos meios e dos valores sociais e históricos de produção linguístico-discursiva. Tem-se uma visão tecnicista, travestida de cientificidade, de objetividade, 
mas que, ao mesmo tempo, trata o sujeito como um ser ideal, racional ou emocionalmente completo (embora se fale de suas vivências e experiências).

O aluno, assim, enquanto sujeito discursivo, é visto como racional, idealmente constituído. Conforme Bakhtin/Volochinov (2011), trata-se de uma concepção de sujeito ideal, que tem um desenvolvimento esperado idealisticamente, conforme sua estrutura cognitiva, e que depende, por isso, de estímulos externos para completar seu desenvolvimento já esperado. Ainda segundo Bakhtin/Volochinov (op. cit.), a consciência tem outros fundamentos, todos sociológicos, ou seja, sociais, históricos, culturais, ideológicos.

A divisão do trabalho, na formação de professores, entre aqueles que produzem conhecimento e aqueles que executam o produto do trabalho intelectual, possibilita pensar, de algum modo, no processo de alienação dos professores em relação às condições de produção das práticas de redação na escola.

A questão final que fica, como horizonte para futuras pesquisas, é: em que medida essas concepções e esses pressupostos estão ainda presentes em nossas políticas e práticas linguísticas de ensino de texto/redação?

\section{Referências}

BAKHTIN, Mikhail. (VOLOCHÍNOV) Marxismo e filosofia da linguagem. São Paulo: Hucitec, 2011.

BAKHTIN, Mikhail. Problemas da poética de Dostoiévski. Rio de Janeiro: Forense Universitária, 1998,

O freudismo: um esboço crítico. São Paulo: Perspectiva, 2010.

Estética da criação verbal. São Paulo: Martins Fontes, 2013.

BRASIL. Lei de Diretrizes e Bases da Educação. Brasília: MEC, 1971.

O ensino de língua portuguesa e literatura brasileira no $2^{\circ}$ grau: sugestões

metodológicas. Brasília: MEC/Secretaria de Ensino de $1^{\circ}$ e $2^{\circ}$ graus, 1981.

CLARE, Nícia de A. Verdini. Ensino de língua portuguesa: uma visão histórica. Revista Idioma, no 23, IL/UERJ, 2003.

GERALDI, João W. (Org.) O texto na sala de aula: leitura \& produção. Cascavel:

Assoeste, 1984.

GINZBURG, Carlo. Mitos, emblemas, sinais: morfologia e história. São Paulo: Martins Fontes, 1986.

MEDVIÉDEV, Pável N. O método formal nos estudos literários: introdução crítica a uma poética sociológica. São Paulo: Contexto, 2012.

MORTATTI, Maria do Rosário L. O texto na sala de aula: uma revolução conceitual na história do ensino de língua e literatura no Brasil. In: SILVA, L. L. M.; FERREIRA, N.

S. A.; MORTATTI, Maria do Rosário L. O texto na sala de aula: um clássico sobre ensino de língua portuguesa. Campinas: Autores Associados, 2014.

SOARES, Magda B. ; NASCIMENTO, Edson. C. Técnica de redação: as articulações linguísticas como técnica do pensamento. Rio de Janeiro: Ao Livro Técnico, 1979.

VEYNE, Paul. Como se escreve a história. Brasília: Editora da UnB, 1992.

VOLOSHÍNOV, Valentin. A construção da enunciação e outros ensaios. São Carlos, SP: Pedro \& João Editores, 2013. 